\title{
LiCENSURE System OF EDUCATION Professionals: A Case StUdy in the UAE
}

\author{
Rawdha Almarar, Amani Alkhodari Doaa Alterri, and Joanna Kalaani \\ Ministry of Education, Abu Dhabi, UAE
}

\begin{abstract}
Teachers are the most critical factor in students' learning among all school-level aspects. Many countries including the United Arab Emirates (UAE) introduced licensure systems to ensure that the teaching profession as well as other educational professions are governed by professional standards and practitioners of education are meeting these standards. In this paper, we address the Educational Professions Licensure system implemented by the Ministry of Education (MOE) in the UAE in terms of its design, components, implementation tools, processes, and challenges. This paper highlights the foundations of the licensure system along with the procedure of licensing education professionals and it demonstrates the implementation of education licensure national tests. In addition, it explains the challenges of introducing the licensure system along with the future plans.
\end{abstract}

\section{KEYWORDS}

Licensure system, Education, MOE, UAE

\section{INTRODUCTION}

One important way of maintaining high quality of education can be through professional licensure of education professionals. This concept has been adopted by several countries worldwide among which is the United Arab Emirates.

Professional licensure regulates professionals working in the education field and ensures that they meet certain requirements, and it usually serves as a gateway to a career. In a country like the United Arab Emirates (UAE) with more than 200 nationalities from diverse cultural backgrounds, professional licensure gains a special importance in the country's educational system as a means of ensuring that any education professional who interacts with students respects their culture and provides them with the best of knowledge and education [1].

The Ministry of Education in the UAE has adopted a new policy for licensure to regulate teaching and other education professions. It plays a vital role in ensuring high levels of capability and providing high-quality education to students through qualified education professionals with sufficient subject-matter and pedagogical knowledge, who can keep up with the recent requirements of education and who are keen to be role models for their students. Whether for teachers, school leadership, or other school professions, the ministry's license assesses if UAE-based education professionals are equipped with sufficiently high levels of know-how and competence to compete globally. It is worth noting here that the model presented in this paper is not necessarily suitable for countries, but it can suggest how countries without licensure processes can start adopting such policy. Nonetheless, it is advisable for each country to investigate all aspects of its infrastructure and implementation before selecting the system that best matches its goals and objectives. 
The objective of the paper is to share the UAE experience in licensing education professionals and showcase licensure components, types, tools, processes, and challenges.

This paper highlights the UAE educational professions license for K-12 educators, delivered through the licensure system of the country's Ministry of Education. It describes the educational professions licensure system in terms of the rationale behind the policy, license added value, license components, types, and target groups. The paper also presents the tools that were built to support the licensure policy and showcases the process of implementation. The paper concludes with a description of current plans for further enhancement of the educational professions licensure system in the UAE.

\section{Literature Review}

For more than two decades, policymakers in different countries worldwide have developed initiatives in educational systems to improve schools and foster the quality of teaching [2]. This includes efforts towards improving the level of education professionals through professional licensure.

Some systems require teachers to be officially licensed while others only require a relevant degree to be appointed as a teacher. Some educational systems further require teachers to undergo professional training to ensure they are well trained and competent. For example, the educational system in Malaysia does not require a license as a condition for teachers to teach. However, having a certificate in education or higher is required for appointment to teaching positions [3].

Research findings around the globe have shown that both the education teachers receive and the licensure they undergo have a significant role in shaping their practices and beliefs [4]. Many educational systems world-wide require a professional license before working in the education field. The requirements and criteria for these licensing systems vary among countries. Some licensure systems, such as those in most states of the USA, require successful completion of one or more assessments along with minimum education requirements as main components [3] [5]. In the USA, research in this regard has shown two approaches to measuring the impact of licensure. One approach argues that strict licensing requirements such as tests ensure that only candidates who can help students achieve at or above the median scores are the ones to be admitted into the educational sector [6]. An alternative approach suggests that the added value provided by the teacher should be examined rather than the sue of quantitative measures of student test scores[6].

Similarly in England and Wales, all teachers are required to pass literacy, numeracy, and Information and Communications Technology (ICT) tests [7]. Some research has been conducted to study the relationship between the licensure test of teachers and their performance effectiveness in classroom [8]. In Australia, readiness for teaching has been based on successful completion of an accredited teacher education program or a recognized qualification. This has been the case until 2012 when the Queensland government required its early childhood and primary school teachers to complete standardized tests in literacy, numeracy, and science [7]. The government of Queensland believes that witnessing improved outcomes in students' performance in literacy, numeracy, and science can be facilitated by the availability of well-prepared teaching workforce especially in the early years of educational study [9]. Their argument for introducing licensing tests is based on the public policy and interest in enhancing the quality of teachers and student learning outcomes. On the other hand, some researchers argue that teacher licensure is poorly related to teacher success in the classroom and that it is rather the experience that the teacher gains which can play a role in the achievement of students [10]. 
In addition, other licensure systems, as in [11], are based on specific frameworks of professional training such as the fields of study, the required skills, and the number of practicum days. Completion of such training programs allows for the entry into the teaching profession in many countries. This is particularly applied in Massachusetts which has 70 educator preparation providers and 2,000 programs in colleges, universities, and other providers[12]. According to [13], constructing a solid professional development system with different guiding approaches for teachers can help in supplying candidates who are committed to career-long learning. In Philippines, the whole teacher education program was created and developed for the purpose of training potential teachers to teach in junior high schools [14]. Similarly, authors in [15] strongly believe that measuring teacher quality should be based on academic coursework requirements.

In Table1, a detailed study on several worldwide licensing systems is summarized. The table explains the requirements for each licensing system in several countries/states along with the license duration. The table shows that some licensing systems, for example in some states in the USA, are based on assessment tests, while in other countries systems are based on education program degrees and teaching experience. The licensure duration in both Massachusetts and Australia is 5 years whereas in New Zealand and South Australia it is 3 years only. The state of Tennessee in the USA has the longest license duration of 6 years compared to the other countries/states in the table. It can also be noticed that all territories above require candidates to complete a Teacher Education Program as part of the licensure process.

Table 1: Summary of Licensing Systems

\begin{tabular}{|c|c|c|c|c|c|}
\hline Country & State-based & Country-based & Licensing Requirements & License Name & $\begin{array}{l}\text { License } \\
\text { Duration }\end{array}$ \\
\hline \begin{tabular}{c|c} 
USA \\
(Massachusetts)
\end{tabular} & $\begin{array}{c}\text { Yes } \\
\text { (Massachusetts) }\end{array}$ & No & \begin{tabular}{|l|} 
1- Holds an Initial License \\
2- Has been employed for at least three years \\
and has completed a one-year induction program \\
3- Has completed one of the following: \\
- An approved licensure program for the Professional License \\
- A program leading to eligibility for master teacher status \\
- Master's or higher degree with at least 12 credits of graduate level courses $[\mathbf{[ E ]}]$
\end{tabular} & Professional License & 5 years \\
\hline $\begin{array}{c}\text { USA } \\
\text { (Tennessee) }\end{array}$ & $\begin{array}{c}\text { Yes } \\
\text { (Tennessee) }\end{array}$ & No & $\begin{array}{l}\text { 1- Holds a bachelor's degree from a regionally accredited college or university } \\
\text { 2- Has completed approved educator preparation program } \\
\text { 3- Has met all professional assessment requirements } \\
\text { as specified by the State Board of Education } \\
\text { 4- Has met requirements in at least one area of endorsement|[17| }\end{array}$ & Professional License & 6 years \\
\hline Australia & No & $\begin{array}{c}\text { Yes } \\
\text { (except South Australia) }\end{array}$ & 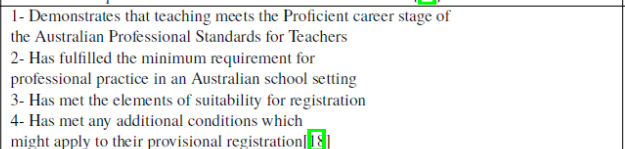 & Full Registration & 5 years \\
\hline England & No & Yes & $\begin{array}{l}\text { 1- Holds an undergraduate degree } \\
\text { 2- Has followed a program of Initial Teacher Training (ITT) } \\
\text { 3- Has met the minimum requirements in GCSE } \\
\text { English. Math, and Science for teaching at primary level [T] }\end{array}$ & Qualified Teacher Status (QTS) & $\mathrm{NA}$ \\
\hline New Zealand & No & Yes & $\begin{array}{l}\text { 1- Holds an approved New Zealand Initial Teacher Education (ITE) qualification } \\
\text { 2- Has gone through police clearance and medical fitness [E0] }\end{array}$ & Full Certification & 3 years \\
\hline $\begin{array}{c}\text { Canada } \\
\text { (Ontario) }\end{array}$ & Yes (Ontario) & No & $\begin{array}{l}\text { 1- Holds a post-secondary undergraduate degree } \\
\text { 2- Has completed an initial teacher education program } \\
\text { 3- Has a proof of language proficiency } \mid[\mathbb{Z} \mid\end{array}$ & Certificate of Qualification and Registration & $\mathrm{NA}$ \\
\hline South Australia & Yes (South Australia) & No & $\begin{array}{l}\text { 1- Holds an approved undergraduate teacher education qualification of at least } 4 \text { years OR } \\
\text { an approved postgraduate teacher education qualification for at least } 1 \text { year } \\
\text { 2- Has completing a Mandatory Notification Training (MNT) } \\
\text { 3- Has a Working with Children Check (WWCC) } \\
\text { 4- Has a proof of language proficiency [2] }\end{array}$ & Full Registration & 3 years \\
\hline
\end{tabular}

\section{UAE Ministry of Education Licensure System}

The Ministry of Education (MOE) governs the educational sector in the UAE for both general education and higher education (REF). As for the licensing, the MOE is exclusively in charge of issuing the educational professions license to education professionals, and the licensure process is 
carried out through three departments which include: the Department of Professional Licensure, the Department of National Tests Development, and the Department of National and International Test Administration.

This section addresses the rationale behind the UAE educational professions license, the license added value, and the license components. It also discusses the license types and target groups as well as the tools that were built to support the licensure policy. Moreover, this section presents the process of licensing education professionals.

\subsection{Rationale Behind the UAE Educational Professions License Policy}

The concept and policy of licensure was launched to establish a robust educational system in the country that is of high quality to act as a driver to achieve the UAE centennial vision of leading in education excellence [23].

One of the major factors that indicated a need for such a policy was the level of diversity of nationalities in the UAE which has consequently created a diversity of educational curriculums in the country as well as a diversity of academic backgrounds of education professionals. Another factor was the major reforms that occurred in colleges of education and teacher programs along with the direction of the country to strengthen subject matter expertise and pedagogical practices.

Therefore, the system was built on extensive international best-practice studies conducted by the ministry starting 2013 where the licensure concept was approved. This was then followed by the approved educational standards in 2016 and the official licensure examination launch in 2018. The policy was designed to ensure that professionals have obtained the required academic qualifications and possess pedagogical and subject-matter knowledge by undergoing professional tests, making the UAE the first Arab country to develop and implement a system for licensing professionals in the educational sector.

\subsection{Educational Professions License Added Value}

The Educational Professions Licensure System has been established to enhance the quality of the education system by ensuring that all teachers and other education professionals possess the minimum acceptable subject-matter and professional standards. Specifically, the system main objectives are:

- Ensure recruitment and retention of teachers and other education professionals are based on clear standards

- Contribute to improvement of teacher education programs to be guided by both academic and professional standards

- Limit the variability of education professionals' ability levels

- Continuously develop education professionals and raise their level of competency

- Contribute to enhancing the quality of student learning according to modern and global practices

- Invest in the education or research of distinguished practitioners

- Identify distinguished workers 


\subsection{Educational Professions License Requirements}

The license is issued upon completion of four components:

1. Registration on the system portal.

2. Academic certificate recognition through attestation or equivalency of an academic degree.

3. Passing subject-matter and pedagogical tests. These tests vary based on the target groups. The tests can be waived if the professional holds a recognized international educational license.

4. Compliance to the UAE's Education Code of Conduct

\subsection{Educational Professions License Types and Target Groups}

The educational licensure targets three main focused groups, which are Teachers, School Leadership, and School Professions. Accordingly, there are three types of the educational professions license: Teacher License, School Leadership License, and School Professions License. The Teacher License targets all teachers in schools while the School Leadership License targets leadership professions such as Principal, Vice Principal, and middle leadership. The School Professions License targets all other professionals working in schools, such as Lab Instructor, Librarian, and Assistant Teacher among other professions.

The license for all categories can be obtained after passing tests and meeting certain requirements. For teachers, the license is obtained by passing two tests, one in pedagogy and the other being a subject-matter test. School professions and school leadership must pass one test only which is related to their profession in order to obtain the license.

To facilitate the licensure process and avoid creating a bottleneck in recruitment two license statuses were established which are:

- Transitional License status: Given upon registration and meeting some requirements.

- Certified License status: Given upon the completion of all licensure requirements.

\subsection{Process of Licensing Education Professionals}

Education professionals can obtain either a certified license or a transitional license based on satisfying certain conditions. Two conditions need to be fulfilled to obtain the certified license:

- System registration

- Passing tests related to the pursued license type

- Obtaining certificate equivalency or attestation of the highest educational qualification

In order to obtain the transitional license, education professionals should meet the following conditions:

- System registration 


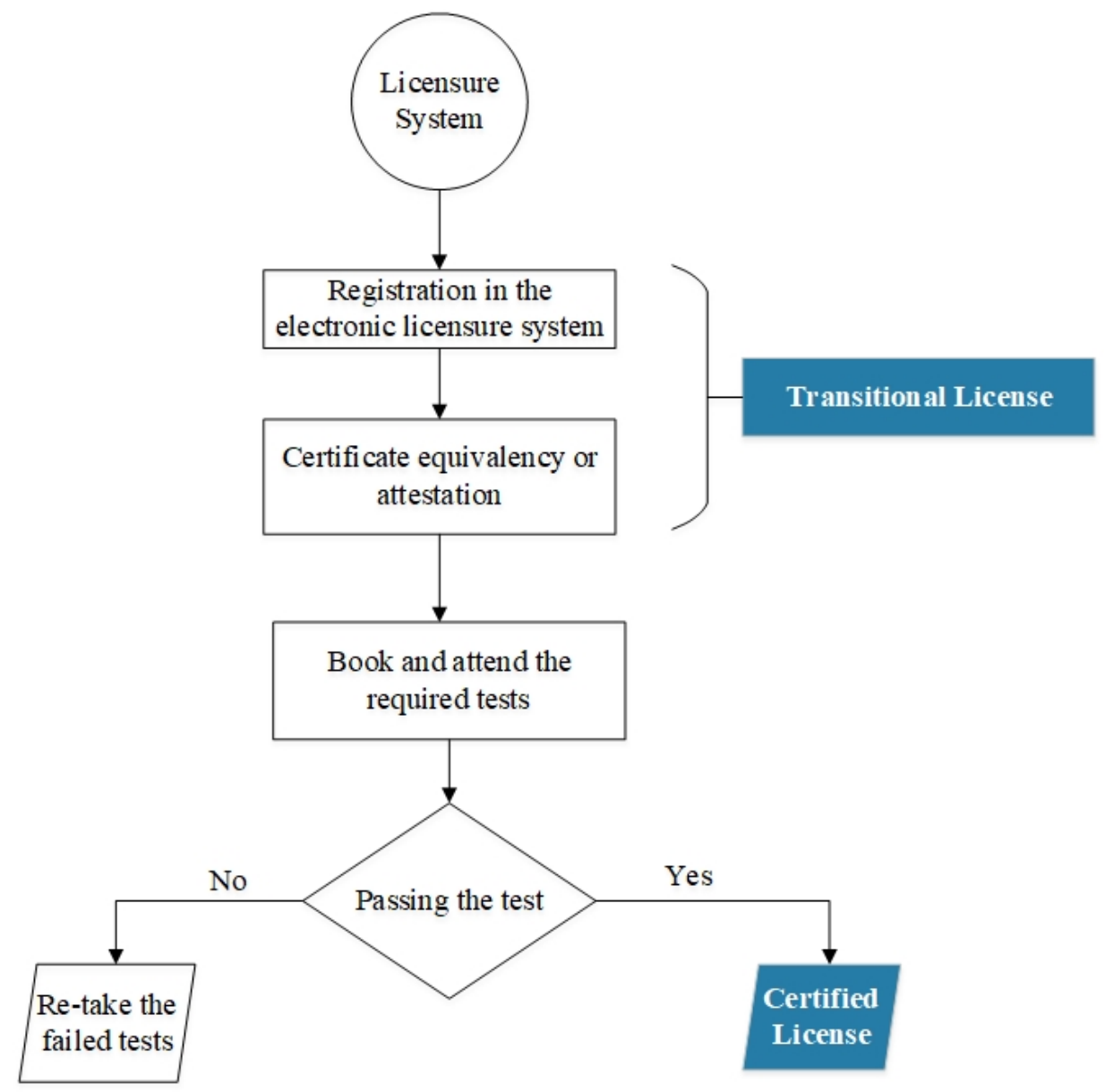

Figure 1: Process of Licensing Education Professionals

- Starting the process of certificate equivalency or attestation of the educational qualification

The flow chart presented in Figure 1 shows the steps for obtaining the educational professions license. Firstly, all education professionals need to register in the educational professions licensure system electronically, providing all mandatory personal and professional information. They must show evidence of certificate equivalency or attestation in the system by providing the certificate equivalency or attestation number. Applicants will then be eligible to obtain the transitional license and work towards meeting the remaining requirements to obtain the certified license. Then, candidates must book the required tests. To increase the fairness of the procedure, each education professional is provided with three attempts to pass the subject-matter test and another three attempts to pass the pedagogy test, allowing a one-month period between attempts for the purpose of training and preparation. In this regard, MOE has established a partnership with local higher education institutes to provide free-of-cost upskilling training to any interested professionals to prepare for the tests.

\subsection{Educational Professions Licensure Tools}

The two major tools used in the licensure process are the Educational Professions Standards and the National Educational Tests. This section highlights how these tools were developed. 


\subsubsection{Educational Professions Standards}

The UAE Ministry of Education believes that establishing a solid base for the professional licensure system project through standardization of all educational occupations is crucial to the whole licensing process. The availability of professional national standards and frameworks governs the performance of professionals in the educational sector, guides the process of licensing and developing licensure national tests, and serves as a platform for any future educational initiatives. Hence, the development of such standards can be considered a focal part of the professional licensure.

The MOE followed a systematic process to develop the standards to develop the standards that govern the licensure system. It consisted of:

1. Forming a committee of national entities as well as project management and project execution teams

2. Hiring UAE-based experts to develop professional standards

3. Reviewing international standards for educational practitioners

4. Engaging expert stakeholders in different stages of the process as necessary

5. Validating the developed national standards through several international validators

6. Submitting deliverables and occupation products to the committee for national endorsement

It is worth mentioning that standards once developed and approved are to be reviewed by the expert committee on a regular basis every three or four years, and for maintaining high quality of the standards that are compatible with the scientific and technological updates in the educational field.

\subsubsection{Creation and Implementation of Education Licensure National Tests}

The educational professions licensure tests are standardized computer-based tests that are developed in line with the national standards and international best practices. Standardized test development requires certain steps and procedures to ensure high reliability, validity, and fairness. The tests are designed so that the output reflects if a candidate passed/failed the test as well as the areas that need further improvements.

Test development starts by constructing a framework that is reviewed and endorsed by a national committee comprised of subject matter and assessment experts. Committee members are chosen so that their qualifications, expertise, and affiliations cover the diverse domains of the test construct.

The process of constructing the test framework development begins with thorough research that involves collecting benchmarking references as well as national and international standards. Subsequently, test specifications are established based on defining test construct domains including the set of knowledge, skills, and competencies that will be measured in addition to the purpose of each test, the targeted test-taking population, and the intended interpretation of the scores. Thereafter, the framework domains are classified into topics and subtopics.

Test specifications are communicated publicly to the test takers. Beside the specifications mentioned previously, the test guide usually includes additional details that are helpful to support candidates in their test preparations. Hence, the test guide usually includes general information about 
the test such as test duration and the number and type of test questions. It also includes details about test structure, test sections, section weights, and detailed information about the set of knowledge and skills across various topics that will be covered. Finally, test guides have a set of sample questions to allow candidates to familiarize themselves with question types.

After test framework development, the test blueprint is created which outlines details about the test design. Question banks are then developed, and different test forms are assembled using questions from the question bank. The test is conducted, analyzed, scored, and reformed when necessary.

\subsection{Recognition of International License}

The licensure system allows recognition of international professional licenses. The flow chart in Figure 1 below depicts the steps that are needed for an international license to be recognized. Firstly, holders of international licenses need to register in the educational professions licensure system electronically by submitting all mandatory personal and professional information. After that, they must show evidence of certificate equivalency in the system and apply for the verification process. Once they pass the verification process, they are eligible to obtain the certified license. Otherwise, they must undergo the MOE licensing steps explained in the previous subsection.

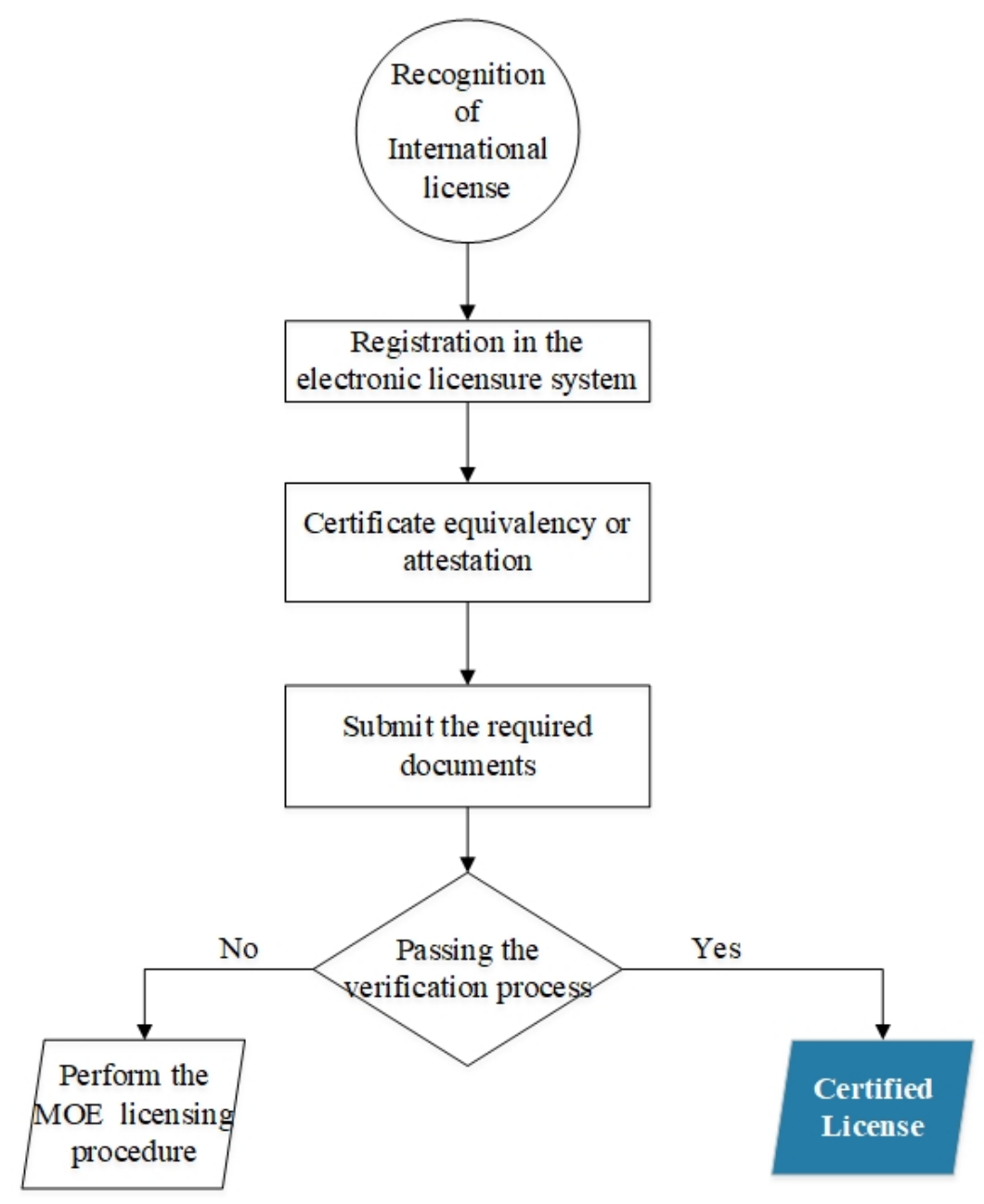

Figure 2: Recognition of International License 


\subsection{Renewing the License}

The education professional license is valid for four years during which the education professional is expected to maintain 100 hours of continuous professional development annually and upload the results of their annual appraisal. If these two requirements are satisfied, renewal of the license is issued for another four years and the cycle repeats.

\section{Challenges of Introducing the Educational Professions Li- CENSE IN THE UAE}

The preparation and implementation phases of the educational professions licensure system in the UAE faced several challenges. One such challenge is the diverse national system of the UAE which includes 200 nationalities and multiple education curriculums [1]. Building high-quality, standardized computer-based tests that match the needs of such diverse curriculum unsurprisingly requires extensive time and effort.

Introducing this licensure system for the first time in the UAE to in-service education professionals has created a big challenge for several reasons. Firstly, requiring assessment tests from this target group caused some objections from teaching and other staff, as with many new policies and initiatives. Secondly, monitoring the registration of all education professionals and coordinating with their schools was a challenge because of the number of candidates all over the country.

\section{Current Ongoing Efforts and Future Plans}

The educational professions licensure project is an ongoing project. Part of this project is expanding the licensure to pre-kg nurseries in the coming years whilst noting that the requirements for that group may differ. Furthermore, the licensure electronic system will go through enhancements to enable schools to better manage their staff, track their performances, and direct the efforts of Continuous Professional Development (CPD) towards areas that need enhancements.

\section{Conclusion}

Education licensure systems have been adopted in several countries and it is important when implementing such systems to reflect on which practice best suits the infrastructure, culture, population number, and aspirations of a country. In this paper, the MOE licensure system governed by the Ministry of Education was discussed highlighting the rationale behind the policy, the added value of the licensure as well as the license types and the tools that were developed to support the policy.

The whole licensing process was explained with all its stages and requirements along with the conditions needed to be fulfilled to obtain the license. The process of licensing education professionals who have international licenses from their countries was also presented. Finally, the challenges of introducing this project to the education sector in the UAE were shared as well as future plans.

\section{ACKnOwledgment}

The authors of this paper would like to acknowledge the efforts of the Ministry of Education in enabling the employees and granting approval to share the overall experience. The authors confirm there are no conflict of interest involve with any parties in this case study. 


\section{REFERENCES}

[1] u.ae, "Fact sheet," https://u.ae/en/about-the-uae/fact-sheet. Cited on page(s): 33, 41

[2] L. Darling-Hammond, "Evaluating teacher effectiveness: How teacher performance assessments can measure and improve teaching." Center for American Progress, 2010. Cited on page $(s): 34$

[3] K. M. Salleh, N. L. Sulaiman, and H. Frederiksen, "Comparison of teacher licensing between the united states of america and malaysia: Implementation and practical implication," Education Journal, vol. 3, no. 3, pp. 190-194, 2014. Cited on page(s): 34

[4] B. Ahmadianzadeh, Z. Seifoori, and N. Hadidi Tamjid, "Exploring efl teachers' beliefs about and practices of learner autonomy across experience and licensure," Innovation in Language Learning and Teaching, vol. 14, no. 2, pp. 97-113, 2020. Cited on page(s): 34

[5] E. Grovenstein, "Teacher licensure in north carolina. concepts." Hunt Institute, 2015. Cited on page $(s): 34$

[6] B. Larsen, "Occupational licensing and quality: Distributional and heterogeneous effects in the teaching profession," Available at SSRN 2387096, 2013. Cited on page(s): 34

[7] R. Mawdsley and J. Cumming, "Certification of teachers, pre-service teacher education, tests and legal issues in australia and the united states of america (us): Part a context, and us history," International Journal of Law \& Education, vol. 16, no. 1, p. 23, 2011. Cited on page $(s): 34$

[8] J. Cowan, D. Goldhaber, Z. Jin, and R. Theobald, "Teacher licensure tests: Barrier or predictive tool? working paper no. 245-1020." National Center for Analysis of Longitudinal Data in Education Research (CALDER), 2020. Cited on page(s): 34

[9] J. Cumming and R. D. Mawdsley, "Certification of teachers, pre-service teacher education, tests and legal issues in australia and the united states of america (us): Part b implications for queensland and australia," International Journal of Law and Education, vol. 16, no. 1, pp. 65-86, 2011. Cited on page $(s): 34$

[10] R. Buddin, G. Zamarro et al., "Teacher quality, teacher licensure tests, and student achievement," Santa Monica, CA: RAND, 2008. Cited on page $(s): 34$

[11] M. M. G. Sywelem, "Accreditation models in teacher education: The cases of united states, australia and india," International Journal of Education and Research, vol. 2, no. 3, pp. 1-12, 2014. Cited on page(s): 35

[12] J. Cowan, D. Goldhaber, and R. Theobald, "Massachusetts educator preparation and licensure," 2017. Cited on page(s): 35

[13] L. Darling-Hammond, "One piece of the whole: Teacher evaluation as part of a comprehensive system for teaching and learning." American Educator, vol. 38, no. 1, p. 4, 2014. Cited on page (s): 35

[14] J. Cristobal, "Licensure examination for teachers (let): A quality control towards k-12 curriculum efficacy," Journal of Critical Reviews, vol. 7, no. 11, pp. 168-171, 2020. Cited on page $(s): 35$ 
[15] B. Larsen, Z. Ju, A. Kapor, and C. Yu, "The effect of occupational licensing stringency on the teacher quality distribution," National Bureau of Economic Research, Tech. Rep., 2020. Cited on page(s): 35

[16] M. D. of Elementary and S. Education, "Teacher licensing," https://www.doe.mass.edu/ licensure/academic-prek12/teacher/. Cited on page(s): 35

[17] D. of Education, "Educator licensure," https://www.tn.gov/education/licensing/ educator-licensure.html. Cited on page( $s)$ : 35

[18] A. I. for Teaching and S. Leadership, "Become a registered teacher," https://www.aitsl.edu. au/prepare-to-be-a-teacher/become-a-registered-teacher. Cited on page $(s): 35$

[19] usas, "Becoming a teacher in the uk," https://www.ucas.com/teaching-in-the-uk. Cited on page $(s): 35$

[20] T. C. of Aotearoa New Zealand, "Applying for registration," https://teachingcouncil.nz/ getting-certificated/for-beginning-teachers/applying-for-registration/. Cited on page(s): 35

[21] O. C. of Teachers, "Requirements," https://www.oct.ca/becoming-a-teacher/requirements. Cited on page(s): 35

[22] T. R. B. of South Australia, "Teacher registration," https://www.trb.sa.edu.au/ registration-requirements. Cited on page $(s)$ : 35

[23] u.ae, "Uae centennial 2071," https://u.ae/en/about-the-uae/strategies-initiatives-and-awards/ federal-governments-strategies-and-plans/uae-centennial-2071. Cited on page(s): 36 
International Journal of Education (IJE) Vol.9, No.4, December 2021 